\title{
The role of bridging organizations in environmental management: examining social networks in working groups
}

\author{
Adam A. Kowalski ${ }^{1}$ and Lekelia D. Jenkins ${ }^{2}$
}

\begin{abstract}
The linkage of diverse sets of actors and knowledge systems across management levels and institutional boundaries often poses one of the greatest challenges in adaptive management of natural resources. Bridging organizations can facilitate interactions among actors in management settings by lowering the transaction costs of collaboration. The Center for Ocean Solutions (COS) is an example of a bridging organization that is focused on linking actors within the ocean sciences and governance arena through the use of working groups. This research examines how network connections between group members affect working group functionality and, more specifically, whether cohesive network structures allow groups to more effectively achieve their goals and objectives. A mixedmethods approach, incorporating both qualitative and quantitative data collection and analysis methods, is employed to understand the structural characteristics of COS working groups. The study finds that cohesive network structures are not associated with increased working group functionality. Strong, centralized leadership is a better predictor of working group success in achieving goals and objectives.
\end{abstract}

Key Words: bridging organizations; environmental management; social network analysis

\section{INTRODUCTION}

The linkage of diverse sets of actors and knowledge systems across management levels and institutional boundaries often poses one of the greatest challenges in adaptive management of natural resources (Berkes 2002, Folke et al. 2005, Ostrom 2005, Armitage et al. 2007). Bridging organizations offer a means to improve environmental management outcomes by spanning the science-policy interface to allow for the effective sharing of data, information, and knowledge. Bridging organizations are institutions that use specific mechanisms such as working groups to link and facilitate interactions among individual actors in a management setting. By lowering the transaction costs of cooperation and collaboration through the coordination of tasks, trust building, and social learning, bridging organizations help establish communities of practice (Folke et al. 2005, Olsson et al. 2007, Berkes 2009, Crona and Parker 2012). Bridging organizations can thus play a central role in solving socialecological problems through the provision of expert information and opinion to decision makers (Haas 1992).

This study focuses on working groups at the Center for Ocean Solutions (COS). COS, a nonprofit organization led by Stanford University, is an example of a bridging organization that is focused on linking scientists and mangers within the marine/ coastal management arena at the local, regional, and global scales, in part through the use of working groups. Working groups convened by COS aim to engage individuals across academic disciplines and government agencies to solve specific marinerelated environmental problems. Given that bridging organizations and participants invest a substantial amount of resources into designing and implementing working groups, research concerning the functionality and effectiveness of working groups and similar bridging mechanisms is required to see if such initiatives warrant the organizational and individual investment.
We found that working group functionality is positively associated with group leadership, not network cohesion as originally hypothesized. This conclusion is supported both quantitatively though a social network analysis (SNA) and qualitatively through web-based surveys administered to working group members. Although a cohesive network can allow group members to more easily share information and directly communicate with one another, it does not necessarily maximize group-level outputs. A highly centralized network structure, in contrast, allows for a more effective delegation of group tasks and activities as well as a better understanding of group goals and objectives.

\section{BACKGROUND}

\section{Theoretical context}

Bridging organizations can improve environmental management outcomes by connecting actors at different management levels and across sectors to promote group decision making. Bridging organizations are formal organizations that use specific collaborative mechanisms, e.g., hosting working groups, to bring together diverse actors (Crona and Parker 2012). Bridging organizations are organizations that function as an arena for knowledge coproduction, trust building, sense making, learning, vertical and horizontal collaboration, and conflict resolution (Berkes 2009).

Although such organizations vary in size, scope, and formalization, environmental bridging organizations primarily facilitate interactions between actors, both individuals and groups, that might otherwise not communicate (Crona and Parker 2012, Rathwell and Peterson 2012). Working groups are commonly used as a boundary object to facilitate collaboration between scientists and decision makers (Guston 2001). Working groups contribute to the overall management and governance process through knowledge production and issue framing, thereby spanning the gap between science and policy. 
Nongovernmental organizations (NGOs) often act as bridging organizations within the natural resource governance arena. Considerable technical, financial, and personnel resources enable NGOs to effectively link actors across institutional and spatial boundaries (Mitchell 2009). Working groups within a bridging organization can facilitate such efforts by providing a formal mechanism and structure by which actors can interact. The working group structure used by COS is based on the National Center of Ecological Analysis and Synthesis (NCEAS) working group model. Since 1995, NCEAS has aimed to engage a range of scientific collaborators in the discussion and analysis of theory, methods, and data primarily through the use of interdisciplinary working groups (Hampton and Parker 2011). Hampton and Parker (2011) conducted extensive research on the productivity of NCEAS working groups and found that the number of group meetings most influences working group productivity and scientific impact. Such a collaborative environment is believed to yield high degrees of trust, limit conflict, and facilitate creativity (Hampton and Parker 2011). These findings inspired this study to more closely examine the effects of social relations on working group productivity through the use of SNA. This study does not intend to compare results to that of Hampton and Parker since different methodologies were used.

\section{Center for Ocean Solutions}

COS is a nonprofit environmental research organization that has an overall mission to solve the major problems facing the oceans and prepare leaders to confront those problems by focusing on ocean/coastal ecosystems in the natural, physical, and social sciences. To help achieve these goals, COS has established five working groups that "synthesize the latest science and policy on pressing issues to identify critical knowledge gaps and to create a path for turning that information into policy actions" (COS, http://web.archive.org/web/20130328043731/http://www. centerforoceansolutions.org/initiatives/working-groups). As of 2012, working groups included the rapid detection of marine pathogens, climate change and coral reefs, climate change and pelagic predators, coastal hypoxia, and social-ecological resilience in small-scale fisheries.

Working groups are convened to address complex and urgent issues that no one individual alone has the knowledge to solve. Individuals are chosen to participate to increase the scope of issuespecific knowledge and practical solutions to the problem. The selection criteria for each working group are very similar, thereby allowing for intergroup comparison despite different group compositions. Participants are from academia, federal and local government, and NGOs. Group membership ranges from 12 to more than 30 participants. We examined four of the five COS working groups. One working group was not included in this study because the group has formally concluded its activities; therefore, comparable measures of social relations among group members could not be obtained.

\section{METHODS}

Although social relations undoubtedly influence collaborative processes in environmental management, researchers have only limited empirical studies of how social relations affect the functionality of bridging organizations (Bodin et al. 2011, Crona and Park 2012). The use of SNA has the potential to offer valuable and unique insights into this emerging research area. SNA seeks to understand the structural variables of social relations, infer relationships between structural characteristics and various outcomes, examine connections (i.e., structure), among the elements (i.e., actors), and locate areas of networks that can be improved to enhance organizational outputs and outcomes (Freeman 2004, Prell et al. 2009, Bodin et al. 2011). By exploring the relational linkages between actors, SNA can quantitatively and qualitatively analyze the social connections between individuals, subgroups, and larger social systems (Scott 2000).

We used a mixed-methods approach, incorporating both qualitative and quantitative social network analysis methods, to test the primary hypothesis: Working group functionality is positively associated with cohesive network structures.

This hypothesis is based on the proposition that cohesive networks should be more effective at generating group-level outputs, e.g., the achievement of specific goals and objectives. In relation to this study, if the majority of working group members are in direct contact with each other, then it is likely that they will begin to share common ideas and practices (i.e., group homogeneity) about how best to accomplish their goals and objectives (Friedkin 1984, Fujimoto and Valente 2012).

\section{Measures}

Functionality (dependent variable)

Measuring the functionality or performance of networks is inherently difficult because networks are composed of many actors, all whom may have different views of what constitutes a functional network (Koliba et al. 2011). In our study, functionality is defined according to the achievement of specific goals and objectives of each COS working group as stated in working group proposals. This is a network-level outcome otherwise unachievable by individual members and, thus, an appropriate measure of working group functionality (Arganoff 2007, Provan and Kenis 2007, Sandström and Carlsson 2008). The achievement of specific goals and objectives of each COS working group was qualitatively measured from open-ended survey responses and quantitatively measured from closed-ended survey responses from working group members. Working groups were regarded as having low, moderate, or high functionality levels in relation to each other based on a comparative measurement method (Sandström 2011). This is an overall interpretation that took into account both qualitative and quantitative data.

Network structure (independent variables)

Network structure is defined as the relational patterns, such as structural cohesion, that emerge from social interaction between two or more actors (Scott 2000, Freeman 2004). The primary network concepts used in this study to measure structural cohesion were density and centralization. Given the variety of definitions of network cohesion, we used Moody and White's (2003:107) definition: "A group is structurally cohesive to the extent that multiple independent relational paths among all pairs of members hold it together." These network concepts were examined across three time domains in the survey instrument: prior, i.e., before the working group began; current, i.e., when the survey was administered; and potential future, i.e., desired relationships after the working group ends. 
Working groups were regarded as having low, moderate, or high levels of density, centralization, and cohesion in relation to each other. This comparative measurement method, adopted from Sandström's (2011) study of local fishery management, is an overall interpretation based on the structural characteristics of working group networks.

Density measures describe the degree to which a network is connected. Specifically, density is the proportion of ties or connections that are present in given network (Wasserman and Faust 1994). A higher density value indicates that a network is more connected. Centralization is another measure used to examine network-level structure. Centralization measures reflect the overall integration of a network. Larger centralization values indicate that a single actor is more central in the network than the other actors; thus, prominent structural positions are unequally distributed (Wassermann and Faust 1994, Scott 2000).

Centralization measures are derived from centrality. Centrality is an actor-level measure, focusing on the structural characteristics of ties between nodes, which in this case are individual actors (Bodin and Crona 2009). Centrality can describe the most important, powerful, and/or prominent actors located within a network (Scott 2000, Borgatti et al. 2009). This study only analyzed degree centrality and degree centralization. Degree centrality, the most basic of all the centrality measures, is the number and strength of ties an actor has in a network (Prell 2011).

When using density, centralization, and centrality together to examine structural cohesion, it is argued that a highly dense network with low centralization is more cohesive than a highly dense network that also has high centralization. Actors in a more cohesive network have many ties to other group members and are not as reliant on central or prominent actors to connect them; i.e., there are more direct ties between actors (Prell 2011). This follows Moody and White's (2003:107) discussion of network cohesion, in which they state that the "the strongest cohesive groups are those in which every person is directly connected to every other person."

\section{Data collection}

Quantitative and qualitative data were collected via web-based surveys. Surveys were conducted from December 2012 to February 2013.

\section{Sample design}

We analyzed four separate working group networks at COS. From this point forward, working groups will only be referred to by an alphabetical letter (A, B, C, and D) for confidentiality purposes. All working groups formally met between two to four times at the time the survey was administered.

For the purpose of this study, individuals were considered to be a member of a working group if they attended at least one of the working group meetings. Given this criterion, the number of members for each working group were as follows: $\mathrm{A}, \mathrm{n}=18$; $\mathrm{B}$, $n=11 ; C, n=22 ;$ and $D, n=17$. Again for confidentiality reasons, the specific institutional affiliations of individuals within each network are not presented in this study.

A request to participate in the study, i.e., to have one's name listed in the survey instrument, was sent via email to all working group members. Of these working group members, not all responded to the requests to be included in the study. Those individuals that did not respond could not have their name listed in the survey instrument, in accordance with human subjects protections, so no data were collected from or about them. Thus, the percentage of working group members included in the survey for each working group waa as follows: A, 72\%; B, 73\%; C, 64\%; and D, $94 \%$. The response rate for those individuals that completed the survey was expectedly lower: A, 56\%; B, 64\%; C, 59\%; and D, $67 \%$. As is discussed in the analysis, specific analysis methods were used to reliably interpret data sets with low response rates.

\section{Survey design}

A web-based survey was administered that consisted of 27 openended and closed-ended questions. The open-ended questions were intended to elicit qualitative information about the perceived functionality of the specific working group that each respondent belonged to. For example, respondents were asked to discuss aspects of their working group that had most facilitated communication and collaboration between members. Closedended questions were designed to collect quantitative relational or sociometric data. Respondents were asked to rate the quality, intensity, and frequency of certain types of relationships with every other participant in the survey based on a Likert scale system. For example, respondents were asked how closely they worked with group members prior to joining the working group, how closely they now work with group members, and how closely they believe they will work with group members in the future once the working group concludes: $0=$ do not know; $1=$ not closely (e.g., casual interactions at professional meetings); $2=$ somewhat closely (e.g., blue ribbon panel); and $3=$ very closely (e.g., coauthorship). Thus, both directional and valued data were collected for each working group network.

Attribute data about each respondent were also collected. These included demographic data such as age, sex, affiliation, and length of time as group member, the respondent's perception of working group functionality, and the respondent's rating of certain individual qualities of other group members, such as leadership ability and quality of contribution to the group. Each survey participant was asked to rate every other participant in the various categories, as well as their own contribution to and involvement in the group, on a scale of scale of 1 to 4 with 1 being the lowest rating and 4 being the highest rating.

\section{Analysis}

Qualitative analysis

Qualitative data collected from the questionnaires were analyzed using a constant comparison method. Collected responses were compared against each other throughout the research process to identify key themes relating to group functionality and network structure (Corbin and Strauss 2008). All responses to the openended survey questions were read multiple times. Notes were taken during the first reading and then subsequently refined through subsequent readings until clear themes were defined.

\section{Quantitative analysis}

Quantitative network data collected from the survey were analyzed using the social network software package UCINET (Borgatti et al. 2002). Density, centralization, and degree centrality measures were calculated using UCINET functions. Given a total response rate of $62 \%$ of all those who were sent the survey, data collected on nonrespondents were used in the final 
analysis to increase the group member sample. When nonrespondents were included in the data set, the percentage of members included in the survey increased from $56 \%$ to $72 \%, 64 \%$ to $73 \%, 59 \%$ to $64 \%$, and $67 \%$ to $94 \%$ of Working Group A, B, $\mathrm{C}$, and D members, respectively. Because of the use of valued and directional data in this study, density was equal to the average strength of ties over all possible ties (Hanneman and Riddle 2005).

To increase the validity of the network analysis given the incorporation of nonrespondent data, only in-degree measures for centralization and centrality were calculated. In-degree ties specifically describe the prestige or prominence of an actor within a network by measuring the degree to which an actor receives ties from other actors in the network (Hanneman and Riddle 2005). According to one study (Costenbader and Valente 2003), indegree centrality, from which in-degree centralization is then calculated, is a more stable centrality measure than most others when respondents do not respond. The study concludes, "Even at low sampling rates, in-degree had higher correlations between the actual and the sample network measures than all of the other centrality measures with the exception of simple eigenvector centrality" (Constenbader and Valente 2003:291).

\section{RESULTS}

\section{Functionality}

The survey contained two primary open-ended questions that pertained to working group functionality: (1) What aspects of the working group help efficiency and overall functionality? (2) What aspects of the working group are not helping efficiency and overall functionality? Respondents were also able to provide additional comments at the end of the survey. These questions examined the degree to which group members agreed about the functionality of their respective groups. In addition, key variables that affect functionality were also identified through the open-ended questions. Box 1 lists the most common themes in order of frequency.

Qualitatively, working Group A was the most functional and Working Group B was the least functional (Fig. 1). Working Group A members were most positive in comparison to other groups about their group's progress on achieving their goals and objectives and the general functionality of the group. Respondents overwhelmingly attributed the perceived success of the working group to strong leadership. Working Group D members exhibited a high degree of consensus on the goals and objectives as well as the primary problems of the group, notably a geographically dispersed membership and, thus, difficulty in organizing frequent face-to-face meetings. Although Working Group D had only been recently established at the time of survey, group members were positive about their progress toward achieving the group's goals and objectives. Working Group $\mathrm{C}$ members were less positive about the group's productivity and functionality because of a noted lack of communication between members, but still felt that the group was achieving its goals and objectives. Finally, Working Group B members exhibited the least amount of consensus about the functionality of their group, specifically what the goals and objectives of the group were. Respondents in Working Group B often referred to a lack of coordination and unclear member roles as a central problem.

\section{Box 1}

\section{Functionality regarding leadership}

a. Strong leadership is essential for group productivity.

b. Leadership keeps the group focused on specific goals and objectives.

c. Lack of leadership or communication with leader(s) hinders the group's ability to move forward on projects.

\section{Functionality regarding face-to-face interactions}

a. Face-to-face interactions are critical for building and maintaining working relationships.

b. A geographically dispersed group membership makes regular face-to-face meetings difficult.

\section{Functionality regarding communication/interaction}

a. Productivity is hindered by long time spans between communications.

b. Group loses momentum and focus because members are often too busy and overextended with other responsibilities.

c. Low meeting attendance occurs as a result of a lack of communication and momentum.

\section{Functionality regarding institutional/organizational support}

a. Support from the hosting institution/organization reduces administrative burden on group members.

b. Members no longer need to focus effort on meeting logistics and can devote attention toward accomplishing the group's goals and objectives.

Fig. 1. Comparison of quantitative (y-axis: degree that the group is meeting its goals on a scale of $1=$ not at all to $4=$ very) and qualitative (x-axis) measures of working group functionality.

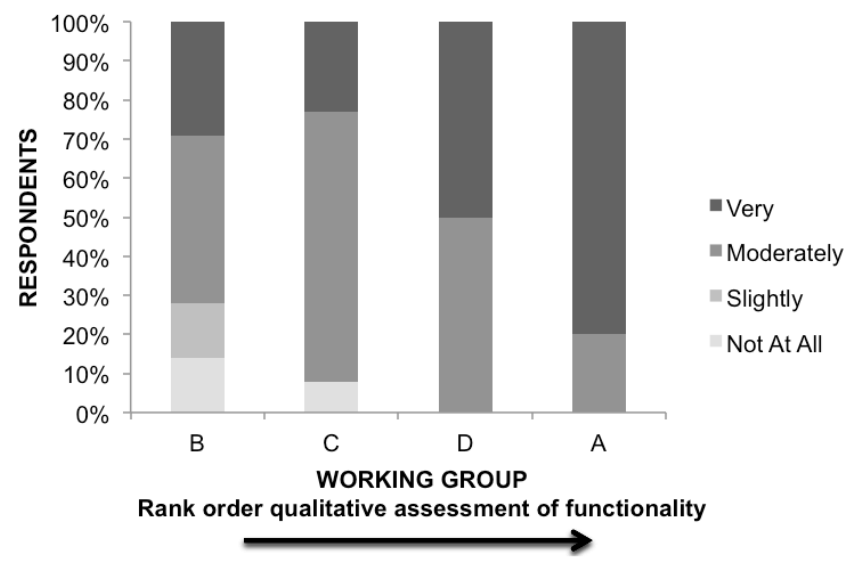


The achievement of goals and objectives was also measured quantitatively. Survey respondents were asked to rate the degree to which they felt their respective working group was meeting its goals and objectives (Fig. 1). Working Group A had the highest percentage of respondents $(80 \%)$ who believed the their working group is very much achieving its goals and objectives, whereas the $\mathrm{B}$ and $\mathrm{C}$ working groups had the lowest percentage of respondents, $29 \%$ and $23 \%$, respectively, who felt their working group is very much achieving its goals and objectives.

Based on the qualitative and quantitative analysis, Working Group A was regarded as the most functional working group, having the greatest degree of positive consensus about the group's progress toward achieving its goals and objectives. Working Group B was interpreted to be the least functional, with the lowest proportion of members that believed the group is very to moderately successful in achieving its goals and objectives and with many members unclear about what the goals and objectives were. The functionality of working groups C and D was not as clearly identified. Although Working Group D respondents were much more positive about group progress than Working Group $\mathrm{C}$ members, there were many noted problems related to the functionality of these groups, including a lack of communication between members. Thus, working groups $\mathrm{C}$ and $\mathrm{D}$ are regarded as moderately functional.

\section{Network structure}

Figure 2 shows how that the density of the workings groups, except for Working Group B, increased across all three time domains. Working Group B had the highest current density value (2.74), whereas Working Group A had the lowest current density value (1.58). The high-density values for Working Group B may be a result of small network size $(n=11$; Scott 2000). The positive changes in the majority of density values indicate that working group networks are becoming more connected through time and stronger working relations are forming.

Fig. 2. Working group density over time.

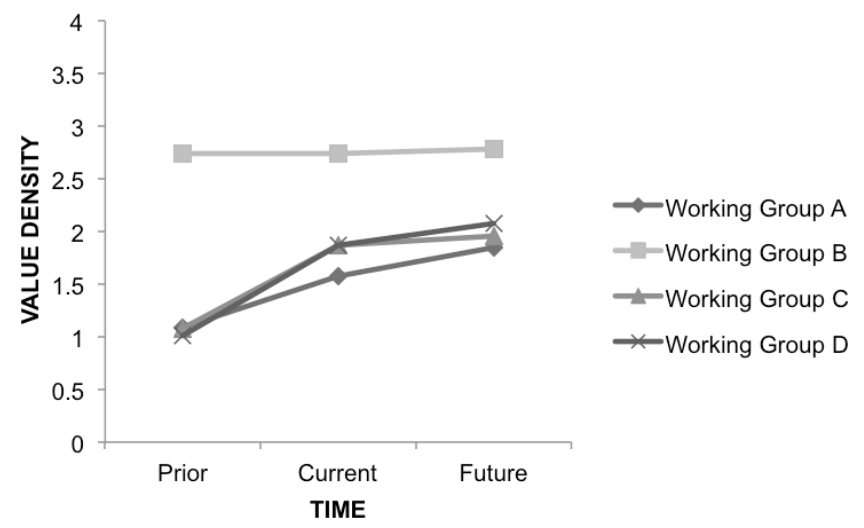

Figure 3 shows that working groups A, C, and D became less centralized from when the working groups were established to the time of the survey, i.e., from the prior to the current time domain. This indicates that the networks are becoming more integrated by not relying as much on prominent members in the group to connect group members. Working Group B had the lowest current centralization value (7.94\%), and the Working Group A had the highest current centralization value (27.53\%). Interestingly, aside from Working Group A, centralization values actually increased from the current to the future time domain. This suggests that there are certain individuals known to be prominent within the working group because of higher in-degree centrality values to whom members would rather be connected to and work with in the future. Thus, desired future connections became unequally distributed within the networks. Attribute data indicate that most of these desired future connections were to older males who are more prominent in their field or are directly associated with COS and its partners. Prestige or prominence outside of the working group setting seemed to be associated with high future in-degree centrality values.

Fig. 3. Working group centralization over time. Centralization measures reflect the overall integration of a network. Larger centralization values indicate that a single actor is more central in the network than the other actors and, thus, prominent structural positions are unequally distributed.

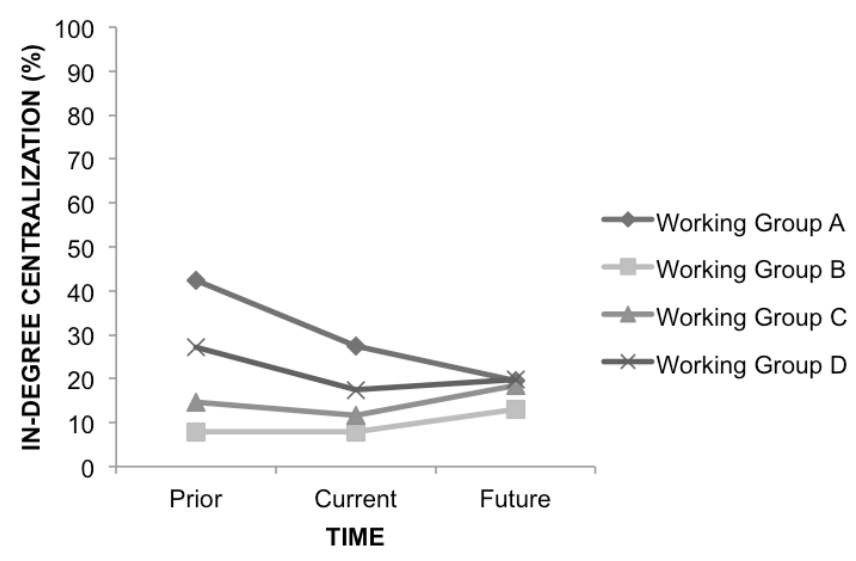

Table 1 shows the cohesiveness of all four working groups. Working Group A was regarded as the most cohesive network, whereas Working Group B was regarded as the least cohesive network. Working groups $\mathrm{C}$ and $\mathrm{D}$ were interpreted to be moderately cohesive because they have both density and centralizations values that fell between those values for working groups $\mathrm{A}$ and $\mathrm{B}$.

Table 1. Assessment of current working group density, centralization, and cohesion.

\begin{tabular}{cccc}
\hline \hline $\begin{array}{c}\text { Working } \\
\text { Group }\end{array}$ & Density & Centralization & Cohesion \\
\hline A & Low & High & Low \\
B & High & Low & High \\
C & Moderate & Low & Moderate \\
D & Moderate & Moderate & Moderate \\
\hline
\end{tabular}

Figure 4 shows the mean individual in-degree centrality of the four working group. The mean individual in-degree centrality for the working groups increased across all three times domains, with the exception of Working Group B. This indicates that on average individual group members formed stronger working relations with one another and, based on the working group experience, 
would like to more closely work with each other in the future. Working Group B only showed a slight increase from the current to the future time domain and no change from the prior to the future time domain. This relative lack of structural network change is most likely because group members knew each other relatively well prior to joining the group. The working group activities, therefore, have not had a significant role in fostering new relationships, unlike those of working groups A, C, and D.

Fig. 4. Working group centrality over time. Centrality can describe the most important, powerful, and/or prominent actors located within a network.

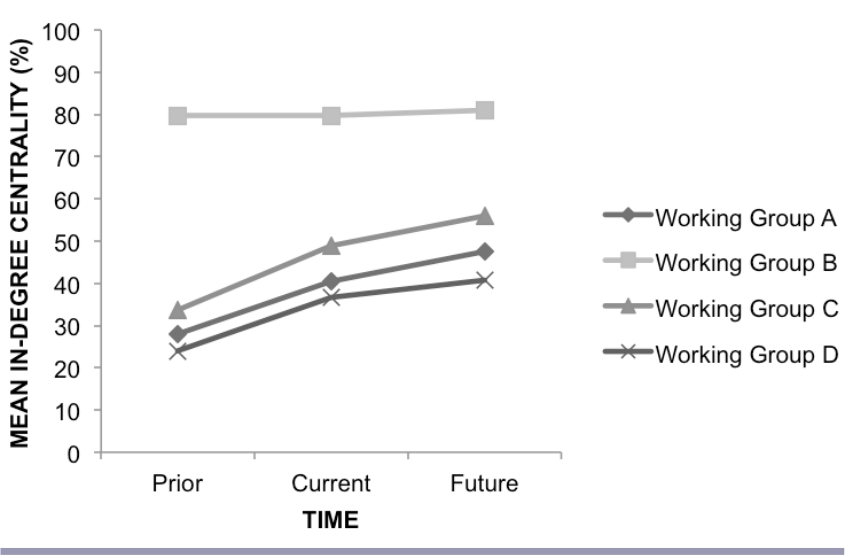

\section{DISCUSSION}

The primary hypothesis, i.e., working group functionality is positively associated with cohesive network structures, was not supported (Table 2). Working Group A, although the most functional group, was the least cohesive network. In contrast, Working Group B was the most cohesive network but the least functional. Even though previous work has shown that the measures used in this study provide an accurate portrayal of the whole network based on a partial network sample (Constenbader and Valente 2003), these results should be cautiously interpreted given that each working group network was only partially sampled.

Table 2. Comparison of working group functionality and cohesion.

\begin{tabular}{ccc}
\hline \hline Working Group & Functionality & Cohesion \\
\hline A & High & Low \\
B & Low & High \\
C & Moderate & Moderate \\
D & Moderate & Moderate \\
\hline
\end{tabular}

Figures 5 and 6 show the current network structures of working groups A and B, respectively. It is important to recognize that in a highly functional network, as exhibited by Working Group A (Fig. 5), there is a clearly defined leadership structure. Although a few individuals are on the periphery of the network, most notably Nodes 11 and 23, one member in particular, Node 42, occupies a very prominent position in the network. This is evidence of a centralized network structure, indicating strong leadership. Survey respondents in Working Group A repeatedly identified Node 42 as someone who is able to effectively communicate and delegate group tasks.

Fig. 5. Working Group A (most functional). Nodes represent individual working group members. Node size represents the member's in-degree centrality. A larger node indicates a higher in-degree centrality value for that member and, thus, more prominence within the network.

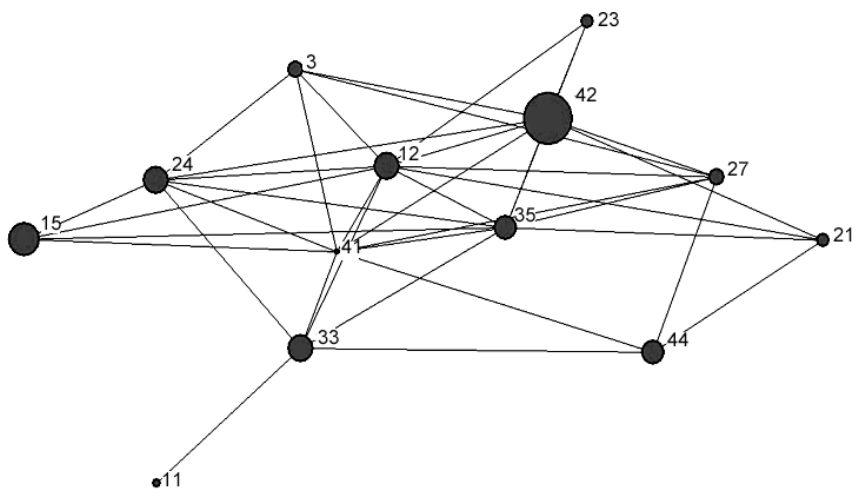

Fig. 6. Working Group B (least functional). Nodes represent individual working group members. Node size represents the member's in-degree centrality. A larger node indicates a higher in-degree centrality value for that member and, thus, more prominence within the network.

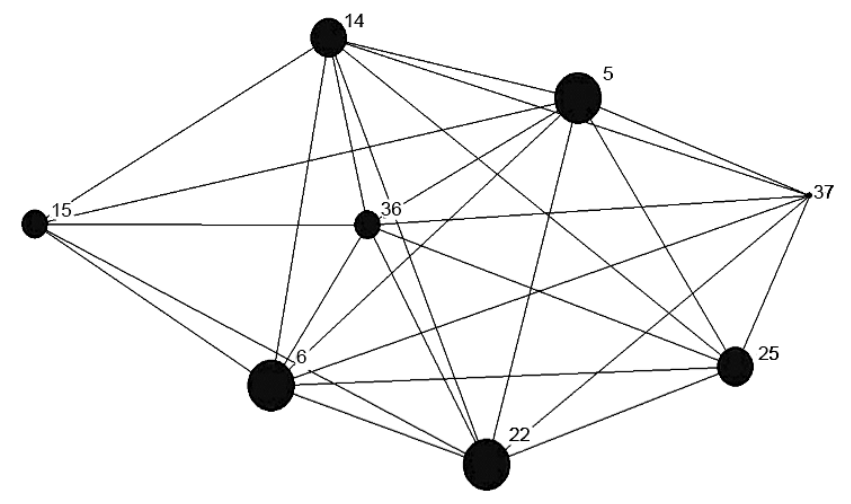

In contrast, Working Group B (Fig. 6), although well connected, does not have a clear leadership structure. Most of the working groups members occupy equally prominent positions within the network. There is a lack of centralization. Survey respondents in Working Group B indicated that the absence of a clear leader has led to poorly delegated member tasks and overall uncertainty surrounding working group goals and objectives.

We concluded that centralization or group leadership is a better predictor of working group functionality than cohesion. These findings are supported by other network studies that show that leadership helps coordinate collective action and maximize group 
benefits in an environmental management setting (Crona and Bodin 2006, Bodin and Crona 2008). Leaders are also instrumental in the self-organizing process because they often possess special skills that allow the group to accomplish initiatives (Olsson et al. 2004). Furthermore, effective leadership in a network setting is marked by the ability to softly guide the group rather than force or coerce the group into certain actions. In a nonhierarchical process, such as is found in COS working groups, there is no top-down command and control structure. This type of leadership is often essential for maintaining a positive group dynamic (Arganoff 2007).

Within environmental bridging organizations, key individuals can serve as liaisons between disciplines to facilitate social learning and help resolve group issues (Crona and Parker 2012). As was also found in our study, these leaders are well-respected and established individuals within the scientific and policy community. Group members were more likely to work with these key individuals in the future, thereby confirming the impactful role that leaders have in a working group setting. Overall, leaders with the ability to communicate across disciplinary boundaries are essential for bridging organizations operating at the sciencepolicy divide.

It is also important to recognize that all four working groups underwent some form of structural network changes regardless of functionality. Actor-level in-degree centrality values increased from the current to the future time domain in all four networks, signifying that group members are forming closer working relationships. Ideally, these strengthened working relationships will continue once the working groups conclude. In addition, working groups A, C, and D are becoming more cohesive through time. Understanding the value of centrality for working group functionality is important because for specialized environmental topics, working groups often consist of people who are actively working together (Crona and Parker 2012). Organizers need to understand whether this model for creating working groups is most effective.

From a bridging organization theory perspective, our results indicate that the working groups are successful in facilitating interactions between individual actors. Whether or not all working groups are achieving their goals and objectives, the working group process is acting as an effective bridging mechanism by positively changing the relational patterns between actors. The technical, financial, and personnel resources that COS is providing to these working groups are creating network structures that allow for more interdisciplinary dialogue and a desire for future collaboration. We found that, for the most part, these structural changes lead to increased interactions and stronger collaborative relationships among working group members. When forming working groups, bridging organizations should consider the degree of familiarity between group members. Prior working group familiarity should be high enough to ensure some level of compatibility but low enough that the working group has the potential to be transformative in forming new relationships.

Future research should aim to measure bridging organization and working group functionality by policy-relevant outcomes, not only structural network qualities and group outputs. The ultimate purpose of these institutions is to produce information and knowledge that can be used to influence policy decisions. This includes reducing knowledge gaps as well as framing complex and dynamic problems.

At this stage, however, COS working groups are presumably too young for group outputs to influence and inform environmental policy in a measurable way. At the time of this study, the oldest of them had only been running for two years. Nonetheless, the findings presented in this study should still be able to improve the functionality of COS working groups and similar task-oriented, interdisciplinary teams in the environmental science fields. Box 2 lists three primary recommendations to improve network functions of such groups. The overall impact of these recommendations, however, may vary from one organization to another given that we did not specifically examine group diversity and institutional factors.

\section{Box 2}

1. Have a defined leadership structure in which group leaders are also accessible and in regular communication with all working group members. Both qualitative and quantitative analysis reveals that more centralized network structures facilitate group interactions by having clearly established short-term and longterm objectives.

2. In the absence of face-to-face group meetings, use other means of communication so group members can discuss the progress of the group in achieving its goals and objectives, thereby maintaining focus and momentum. This will help build and maintain working relationships between members, which survey respondents believed is an important component of working group functionality. Use of other means of communication will require logistical support from the bridging organization to reduce the burden on working group members, most of whom are already busy with other professional commitments.

3. Maintain group focus through defined individual roles. Each member should know what he or she is working toward as well as what other members are contributing to the group. Defined member roles, with specific duties and tasks to accomplish, will help the group maintain focus and productivity even if long time lapses remain between face-to-face meetings. This will require a defined leadership structure to effectively delegate and monitor individual tasks.

COS and other environmental bridging organizations can apply these three recommendations to significantly improve working group functionality. First, each working group's scoping document should clearly identify a group leader and define the group leader's responsibilities to ensure that these key individuals have the necessary authority to resolve any group issues and maintain forward progress. Second, group members should decide, preferably soon after establishment of the group, the frequency of communication that they think will be required to achieve the stated goals and objectives. Accordingly, group leaders should possess the ability to change the frequency of communications to improve functionality. Last, group leaders should assign specific tasks to individual members or have a process in which members volunteer to undertake certain tasks. 
This can help resolve any ambiguity surrounding group member contributions and institute a certain level of individual accountability.

This study contributes to understanding the role that environmental bridging organizations like COS play in spanning the science-policy interface by mapping network structures through time, analyzing select network variables, and examining their association to group functionality. Although this project has scholarly value in examining social networks within a natural resource management context, the study's results can also be used by COS, and potentially by similar organizations, in an applied manner to improve the working group process and, ultimately, the impact bridging organizations have on environmental policy.

Responses to this article can be read online at: http://www.ecologyandsociety.org/issues/responses. $\mathrm{php} / 7541$

\section{Acknowledgments:}

Thank you to the Center for Ocean Solutions and working group members for their participation in this study.

\section{LITERATURE CITED}

Arganoff, R. 2007. Managing within networks: adding value to public organizations. Georgetown University Press, Washington, D.C., USA.

Armitage, D., F. Berkes, and N. Doubleday. 2007. Adaptive comanagement: collaboration, learning, and multi-level governance. UBC Press, Vancouver, British Columbia, Canada.

Berkes, F. 2002. Cross-scale institutional linkages: perspectives from the bottom-up. Pages 293-322 in E. Ostrom, T. Dietz, N. Dolsak, P. C. Stern, S. Stonich, and E. U. Weber, editors. The drama of the commons. National Academies Press, Washington, D.C., USA.

Berkes, F. 2009. Evolution of co-management: role of knowledge generation, bridging organizations and social learning. Journal of Environmental Management 90(5):1692-1702. http://dx.doi. org/10.1016/j.jenvman.2008.12.001

Bodin, Ö., and B. I. Crona. 2008. Management of natural resources at the community level: exploring the role of social capital and leadership in a rural fishing community. World Development 36(12):2763-2779. http://dx.doi.org/10.1016/j. worlddev.2007.12.002

Bodin, Ö., and B. I. Crona. 2009. The role of social networks in natural resource governance: what relational patterns make a difference? Global Environmental Change 19(3):366-374. http:// dx.doi.org/10.1016/i.gloenvcha.2009.05.002

Bodin, Ö., S. Ramirez-Sanchez, H. Ernstson, and C. Prell. 2011. A social relational approach to natural resource governance. Pages 3-28 in Ö. Bodin and C. Prell, editors. Social networks and natural resource governance: uncovering the social fabric of environmental governance. Cambridge University Press, New York, New York, USA. http://dx.doi.org/10.1017/ CBO9780511894985.002

Borgatti, S. P., M. G. Everett, and L. C. Freeman. 2002. UCINET for Windows: software for social network analysis. Analytic Technologies, Harvard University Press, Boston, Massachusetts, USA.

Borgatti, S. P., A. Mehra, D. J. Brass, and G. Labianca. 2009. Network analysis in the social sciences. Science 323:892-895. http://dx.doi.org/10.1126/science.1165821

Corbin, J., and A. Strauss. 2008. Basics of qualitative research. Sage, Thousand Oaks, California, USA.

Costenbader, E., and T. W. Valente. 2003. The stability of centrality measures when networks are sampled. Social Networks 25(4):283-307. http://dx.doi.org/10.1016/S0378-8733(03)00012-1

Crona, B., and Ö. Bodin. 2006. What you know is who you know? Communication patterns among resource users as a prerequisite for co-management. Ecology and Society 11(2): 7. [online] URL: http://www.ecologyandsociety.org/vol11/iss 2/art7/

Crona, B. I., and J. N. Parker. 2012. Learning in support of governance: theories, methods, and a framework to assess how bridging organizations contribute to adaptive resource governance. Ecology and Society 17(1): 32. http://dx.doi. org/10.5751/ES-04534-170132

Folke, C., T. Hahn, P. Olsson, and J. Norberg. 2005. Adaptive governance of social-ecological systems. Annual Review of Environment and Resources 30(1):441-473. http://dx.doi. org/10.1146/annurev.energy.30.050504.144511

Freeman, L. C. 2004. The development of social network analysis. Empirical Press, Vancouver, British Columbia, Canada.

Friedkin, N. E. 1984. Structural cohesion and equivalence explanations of social homogeneity. Sociological Methods \& Research 12(3):235-261. http://dx.doi.org/10.1177/0049124184012003001

Fujimoto, K., and T. W. Valente. 2012. Social networks influences on adolescent substance use: disentangling structural equivalance from cohesion. Social Science \& Medicine 74:1952-1960. http:// dx.doi.org/10.1016/j.socscimed.2012.02.009

Guston, D. H. 2001. Boundary organizations in environmental policy and science: an introduction. Science, Technology, \& Human Values 26(4):399-408. http://dx.doi.org/10.1177/016224390102600401 Haas, P. M. 1992. Introduction: epistemic communities and international policy coordination. International Organizations 46(1):1-35. http://dx.doi.org/10.1017/S0020818300001442

Hampton, S. E., and J. N. Parker. 2011. Collaboration and productivity in scientific synthesis. BioScience 61(11):900-910. http://dx.doi.org/10.1525/bio.2011.61.11.9

Hanneman, R., and M. Riddle. 2005. Introduction to social network methods. University of California Riverside, Riverside, California, USA. [online] URL: http://faculty.ucr.edu/ hanneman/nettext/

Koliba, C., J. W. Meek, and A. Zia. 2011. Governance networks in public administration and public policy. Taylor \& Francis, Boca Raton, Florida, USA. 
Mitchell, R. B. 2010. International politics and the environment. Sage, Thousand Oaks, California, USA.

Moody, J., and D. R. White. 2003. Structural cohesion and embeddedness: a hierarchical concept of social groups. American Sociological Review 68(1):103-127. http://dx.doi.org/10.2307/3088904

Olsson, P., C. Folke, and F. Berkes. 2004. Adaptive comanagement for building resilience in social-ecological systems. Environmental Management 34(1):75-90. http://dx.doi.org/10.1007/s00267-003-0101-7

Olsson, P., C. Folke, V. Galaz, T. Hahn, and L. Schultz. 2007. Enhancing the fit through adaptive co-management: creating and maintaining bridging functions for matching scales in the Kristianstads Vatternrike Biosphere Reserve, Sweden. Ecology and Society 12(1): 28. [online] URL: http://www.ecologyandsociety. org/vol12/iss1/art28/

Ostrom, E. 2005. Understanding institutional diversity. Princeton University Press, Princeton, New Jersey, USA.

Prell, C. 2011. Some basic structural characteristics of networks. Pages 29-43 in Ö. Bodin and C. Prell, editors. Social networks and natural resource governance: uncovering the social fabric of environmental governance. Cambridge University Press, New York, New York, USA. http://dx.doi.org/10.1017/ CBO9780511894985.003

Prell, C., K. Hubacek, and M. Reed. 2009. Stakeholder analysis and social network analysis in natural resource management. Society \& Natural Resources 22(6):501-518. http://dx.doi. org/10.1080/08941920802199202

Provan, K. G., and P. Kenis. 2007. Modes of network governance: structure, management, and effectiveness. Journal of Public Administration Research and Theory 18(2):229-252. http://dx.doi. org/10.1093/jopart/mum015

Rathwell, K. J., and G. D. Peterson. 2012. Connecting social networks with ecosystem services for watershed governance: a social-ecological network perspective highlights the critical role of bridging organizations. Ecology and Society 17(2): 24. http:// dx.doi.org/10.5751/ES-04810-170224

Sandström, A. 2011. Social networks, joint image building, and adaptability: the case of local fishery management. Pages 288-321 in Ö. Bodin and C. Prell, editors. Social networks and natural resource governance: uncovering the social fabric of environmental governance. Cambridge University Press, New York, New York, USA. http://dx.doi.org/10.1017/CBO9780511894985.013

Sandström, A., and L. Carlsson. 2008. The performance of policy networks: the relation between network structure and network performance. Policy Studies Journal 36(4):497-524. http://dx.doi. org/10.1111/j.1541-0072.2008.00281.x

Scott, J. 2000. Social network analysis: a handbook. Sage, Thousand Oaks, California, USA.

Wasserman, S., and K. Faust. 1994. Social network analysis: methods and applications. Cambridge University Press, New York, New York, USA. http://dx.doi.org/10.1017/CBO9780511815478 